\title{
CF1129
}

\section{Service-Life Assessment of Existing Precast-Concrete Structure Exposed to Severe Marine Conditions}

\author{
I. Segura ${ }^{1}$, S. Cavalaro ${ }^{2}$, A. de la Fuente ${ }^{3}$, A. Aguado $^{4}$, and V. Alegre ${ }^{5}$ \\ ${ }^{1}$ Ph.D., Juan de la Cierva Postdoctoral Researcher, Department of Construction Engineering, \\ Universitat Politècnica de Catalunya - Barcelona Tech, Barcelona, Spain. Carrer Jordi Girona 1- \\ 3, Edifico C1, despacho 202. E-08034 Barcelona. SPAIN. Email: ignacio.segura@upc.edu. Tel.: \\ +34-93-401-65-30. Fax: +34-93-405-41-35 \\ ${ }^{2}$ Visiting Professor, Department of Construction Engineering, Universitat Politècnica de \\ Catalunya - Barcelona Tech, Barcelona, Spain. sergio.cavalaro@upc.edu \\ ${ }^{3}$ Associate Professor, Department of Construction Engineering, Universitat Politècnica de \\ Catalunya - Barcelona Tech, Barcelona, Spain. albert.de.la.fuente@upc.edu \\ ${ }^{4}$ Full Professor, Department of Construction Engineering, Universitat Politècnica de Catalunya - \\ Barcelona Tech, Barcelona, Spain. antonio.aguado@upc.edu \\ ${ }^{5}$ Collaborator, Department of Construction Engineering, Universitat Politècnica de Catalunya - \\ Barcelona Tech, Barcelona, Spain. vicente.alegre@upc.edu
}

\begin{abstract}
The overall performance of a concrete structure is considered to be a key issue when determining its service life. The widespread use of precast concrete and consideration of durability as a design parameter in most of the international codes have the goal of achieving concrete structures with better durability. Nevertheless, the early deterioration of concrete is still common in a large number of concrete structures, which reduces the service life. This paper presents a case study of an existing precast concrete cooling tower for a thermal power station subjected to severe marine exposure conditions, which showed symptoms of serious deterioration after operating for three years. The main goal of this study was to clarify the origin of the accelerated deterioration of the structure. Wetting-drying cycles were identified as the main cause of the
\end{abstract}


early deterioration of the structure. Furthermore, estimations on its remaining service life were made considering the accelerating effect of the wetting-drying cycles. Finally, the variation in the safety factor of the main structural elements was evaluated.

Keywords: Marine structures; concrete structures; durability; structural analysis; service life Introduction

The corrosion of steel reinforcement is considered to be the most important issue affecting the service life of concrete structures. Among the various sources, chloride-induced corrosion is considered to be the most significant threat to the existing reinforced concrete infrastructure. In most situations, corrosion is initiated by chloride contamination, often in conjunction with an inadequate cover thickness or poor quality concrete. Early signs of deteriorations can be found in many structures. The main reasons for the inadequate performance of concrete structures are poor workmanship and a lack of knowledge concerning the relevant deterioration mechanisms, which results in insufficient planning and incorrect estimations of the environmental effects (Costa and Appleton, 2002).

To produce durable structures, durability must be considered in every step of the project, i.e., design, execution, and operation. The most recent version of the Model Code (fib, 2010) discusses the verification of the limit states associated with durability, considering several degradation phenomena, including chloride-induced corrosion. Although many different codes and standards have introduced durability as a design parameter, there are many structures currently in operation that were built with no or insufficient consideration given to durability. In addition, the use of precast concrete structural elements has increased in recent years. This has made it possible to achieve a more homogeneous and durable concrete quality, and thus more durable structures, which reduces the costs and associated construction times. It is generally 
assumed that precast elements are more durable than similar elements made from ordinary castin-place concrete. Nevertheless, the suitability of placing a given material under a given exposure condition should always be considered.

Most of the research done on chloride-induced corrosion involves laboratory studies or accelerated experiments simulating real conditions. Actually, an increasing number of studies are being conducted on chloride-induced corrosion in real structures (Costa and Appleton, 2002; Medeiros et al., 2013; Shekarchi et al., 2011; Papé and Melchers, 2011; Melchers and Li, 2009). The results of these studies have been very valuable for validating the usefulness of the developed mathematical models and determining the factors that affect the service life of a real structure. This paper presents a case study of a precast concrete structure subjected to severe marine exposure conditions, which exhibited clear signs of reinforcement corrosion after being in service for three years. The main aim of this study was to clarify the origin of the accelerated deterioration of the structure, estimate its remaining service life using the models available in structural codes, and analyze the variation in the safety factor of the structure. Three precast elements of the structure were analyzed: a canal beam, main girder, and roof girder. These elements were selected based on their importance in ensuring both the safety and serviceability of the structure. First, the structural elements are described. Second, the measured chloride penetration profiles are presented, and the degradation process is analyzed. Lastly, a structural analysis is conducted to obtain the safety factor for each element considered, thus estimating its remaining service life.

\section{Research significance}

The research significance of this work is derived from the combined analysis of the durability and structural safety of the structure. The durability analysis provided insights on the origin of 
the premature deterioration of the structure. Furthermore, this analysis made it possible to estimate the effect of wetting-drying cycles on the magnitude of the chloride diffusion coefficient. The structural analysis allowed safety factors to be obtained for each structural element, considering the effect of the reinforcement corrosion on the constitutive materials. To this end, several constitutive equations provided within the scientific literature to simulate the loss of mechanical properties of the reinforcing were considered in this analysis. Furthermore, these results were used to estimate the remaining service life of the structure.

All of the above is of vital importance for the managers of the structure, in terms of decision making related to future investments or payback of the power plant. First, it makes it possible to identify the causes of the early deterioration and thus allows the selection of adequate repair strategies. Second, it allows the repair investment to be prioritized, taking into account the remaining service life of each element. Ultimately, the analysis performed in this paper provides a valuable example regarding the need to include the durability in the design of a structure under severe exposure conditions. The study showed that simplified models are valuable tools for assessing potential problems that might arise during the service life.

\section{Description of case study}

The concrete structure considered in this case study was the cooling tower of a thermal power station plant, made up of precast concrete elements. The structure is located in a region of intense winds from the northeast and east. The sea is located in the southeast direction and is less than $500 \mathrm{~m}$ away from the structure. There are two cooling towers, consisting of several two-story rooms acting as a heat exchanger; hot water is transferred to the upper part of the cooling tower by a canal beam, where it falls and is cooled by a counter-current. The complete cooling system of the power station uses seawater as a coolant. A small amount of sodium hypochlorite is added 
to the coolant to prevent the growth of algae and microorganisms.

The structure is a bi-directional lattice composed of precast reinforced concrete girders and columns. The columns have a maximum height of $19.2 \mathrm{~m}$, with an average separation of 3.3 $\mathrm{m}$, forming a uniform mesh in both directions. The columns have corbels halfway along their height to support the girders, which form horizontal structures at different levels. There are four different girder levels: the anti-noise level (-0.7 m), filling level (+7.7 m), distribution level (+11.6), and roof level (+19.2 m). The roof is composed of a 0.1-m-thick cast-in-site reinforced concrete slab. The internal and external walls of the plant modules are composed of precast concrete panels, with a medium length of $7.5 \mathrm{~m}$ and various heights depending on the level of the structure.

The construction of this structure was completed by the end of 2006, and its commissioning was finished by the middle of 2007. The design service life of the structure was established to be 25 years. After three years of service, the structure showed symptoms of serious deterioration both inside and outside the cooling tower. Together with damage to the external panels, cracks with widths of up to $0.8 \mathrm{~mm}$ were found in the columns, canal beam, and bottom sides of the girders. Furthermore, spalling of the concrete cover due to corrosion of the reinforcement steel was observed in some elements. The details of some of the damage seen in this structure are shown in figure 1 . The damage was more serious in the rooms with a southsoutheast orientation, where the company offices are located.

In 2009, the structure was investigated and repaired for the first time. At that time, a thorough study was also conducted by characterizing drilled concrete cores obtained from the external panels and canal beam. Cores were taken from one side to the other of both elements. Thus, both the inside and outside concrete surfaces could be analyzed. This study made it possible to obtain 
the compressive strength, water permeability, and chloride penetration profiles. The analysis of the structure and samples did not show any evidence of other deleterious reactions in addition to the alkali-aggregate reaction.

Additionally, the concrete cover was measured in some of the elements using the eddy current method during investigations of the structure in 2009 and 2012. The measurements of the concrete cover depth in 2009 were made on cracks identified in each of the elements, although no search for secondary bars was made. The mean values of both measurements are listed in table 1, along with the standard deviations. More than 20 observations were made in the 2009 inspection, with six in the 2012 inspection. There was a large variation in the concrete cover measurements made in 2009. In addition to evidencing variations in the real concrete cover, these variations could also be related to the measurement procedure.

It is important to note that an extensive characterization of the structure and the extraction of samples were not possible at most points because of the operation regime of the plant. Therefore, the information for the analysis was limited to the existing results from previous studies obtained from tests of a limited number of samples. In situations where it is possible, more information regarding the characteristic of the concrete and the ongoing corrosion process should be evaluated to provide a more accurate assessment of the condition of the structure. For instance, given the nature of the degradation process, it would be advisable to appraise the $\mathrm{pH}$ and chloride content that promotes the corrosion acceleration.

\section{Description of the structural elements}

The structural elements considered in the case study are shown in figure 2, and their design parameters are presented in table 2. The XS3 and XA2 exposure classes were chosen for the precast concrete elements of the cooling tower, based on the anticipated exposure conditions of 
the structure. The precast concrete elements were made using cement type CEM I 52.5N/SR (sulfate resisting Portland cement) and crushed limestone aggregates. Furthermore, commercial plasticizer and superplasticizer additives were used. Plain steel reinforcement was used in all the structural elements. All the concrete components were in agreement with the current Spanish Code for Structural Concrete (Ministerio de Fomento, 1998).

The canal beams are U-shaped precast reinforced concrete elements with a height of $2700 \mathrm{~mm}$, width of $1900 \mathrm{~mm}$, and thickness of $200 \mathrm{~mm}$. These elements act as water transport channels, transferring hot water from the heat exchanger to the upper part of the cooling tower to be cooled. Three canal beams are located at each side of the cooling tower. They were fabricated using concrete with a characteristic compressive strength $\left(f_{c k}\right)$ of $35 \mathrm{~N} / \mathrm{mm}^{2}$ and steel type B500S $\left(f_{y k}=500 \mathrm{~N} / \mathrm{mm}^{2}\right.$ and Es $\left.=200000 \mathrm{~N} / \mathrm{mm}^{2}\right)$ for the steel reinforcement. During service operations, a water level of $500 \mathrm{~mm}$ is permanently maintained. The reinforcement elements considered in the analysis are bars with diameters of 10, 12, 16, and $20 \mathrm{~mm}$, and a minimum design concrete cover of $40 \mathrm{~mm}$.

The main girders are straight beams with a rectangular cross-section consisting of precast reinforced concrete. The length of these elements is $7550 \mathrm{~mm}$, with a variable section height along the length (ranging from $645 \mathrm{~mm}$ to $700 \mathrm{~mm}$ ). The main girders were fabricated using concrete with $f_{c k}=35 \mathrm{~N} / \mathrm{mm}^{2}$ and steel type B500S for the steel reinforcement. These elements are located in the intermediate level of the cooling tower. They are directly in contact with hot water and are supposed to be constantly wet. The reinforcement elements considered in the analysis are bars with diameters of 8, 25, and $32 \mathrm{~mm}$, and a design concrete cover of $40 \mathrm{~mm}$. The roof girders are straight beams with a rectangular cross section composed of prestressed and reinforced precast concrete. The length of these elements is $8050 \mathrm{~mm}$, with a 
change in geometry to support a hoop. The roof girders support the weight of the rotors located on the roof. These elements were fabricated using concrete with $f_{c k}=50 \mathrm{~N} / \mathrm{mm}^{2}$; Y1860-S7-type steel $\left(f_{y k}=1860 \mathrm{~N} / \mathrm{mm}^{2}\right.$ and $\left.E_{s}=190000 \mathrm{~N} / \mathrm{mm}^{2}\right)$ was used for the prestressed steel reinforcement, with the B500S type used for the plain steel reinforcement. The roof girders are located on the top level of the cooling tower, and are continuously in contact with the water vapor emitted by the cooling system. The reinforcement elements considered in the analysis are bars with diameters of 8,10 , and $25 \mathrm{~mm}$ for the plain steel reinforcement, and strands of seven wires with a diameter of 0.6 ” $(15.24 \mathrm{~mm})$ for the prestressing steel reinforcement; the design concrete cover is $40 \mathrm{~mm}$ for the plain steel reinforcement and $80 \mathrm{~mm}$ for the prestressed steel reinforcement.

\section{Characterization of drilled concrete cores}

Several core samples were drilled from different structural elements of the cooling tower. The cooling tower is divided into two different modules, related to the different turbines of the thermal power station: rooms 1 to 8 belong to module 1 , and rooms 9 to 16 belong to module 2 . As mentioned in the description of the case study, drilled concrete cores were obtained from the external panels and canal beams. Cores were extracted from both elements, extending from the inside to the outside surfaces. The mean diameter and length of the cores were $99 \mathrm{~mm}$ and 187 mm, respectively. This study allowed to obtain the compressive strength (UNE-EN according with the 12390-3), the water permeability (according with EN 12390-8), and chloride penetration profiles (following the NT BUILD 443 standard). The results are shown in table 3.

The compressive strength obtained do not evidence shortcomings in the concrete quality that can explain the differences observed in the deterioration extent between different parts of the structure, complying with the minimum mechanical requirements established in the Spanish 
instruction and in the project specifications. Furthermore, the depth of water penetration evidences a high quality concrete as defined in the Spanish Instruction, which prescribes that the material should present maximum and average values below $50 \mathrm{~mm}$ and $30 \mathrm{~mm}$, respectively. Regarding the chloride penetration profiles, details on the location and type of element in each sample are given in table 4; during the sample coring process, no evidence of macro- and microcracking was reported. The general procedure employed to obtain the chloride penetration profiles is described in the NT BUILD 443 standard (Nordic Innovation, 1995). For each core sample, seven to nine different depth intervals were analyzed. Because all the elements are exposed to a chloride environment both inside and outside, chloride penetration profiles were assessed for each side of every sample.

A mathematical analysis of the chloride penetration profiles was performed using the accepted analytical solution of Fick's 2nd law derived by Crank (Crank, 1975), and described by equation (1). This equation defines the variation in the chloride-ion content (expressed in terms of a percentage over cement weight) as a function of the depth and exposure time. In equation (1) , $C_{s}$ is the chloride content at the exposed concrete surface (percentage over cement weight), $C_{0}$ is the initial chloride content of the concrete (percentage over cement weight), $d$ is the depth from the concrete surface (m), $D$ is the apparent chloride diffusion coefficient $\left(\mathrm{m}^{2} / \mathrm{s}\right), t$ is the exposure time (s), and erf is an error function.

$$
C(x, t)=C_{s}-\left(C_{s}-C_{0}\right) \cdot \operatorname{erf}\left(\frac{d}{\sqrt{4 \cdot D \cdot t}}\right)
$$

The adjustment of the experimental data to equation (1) was done considering the following data for the exposure time and cement content. The exposure time was fixed at 18.5 months, based on the times for the structure commissioning (July 2007) and extraction of the core samples (January 2009). The cement content was estimated to be $400 \mathrm{~kg} / \mathrm{m}^{3}$ according to the strength of 
the precast concrete $\left(f_{c k}=35 \mathrm{~N} / \mathrm{mm}^{2}\right)$ and considering the applicable codes. Because the chloride ion content is usually expressed as a percentage of the concrete weight, the cement content is needed to obtain the equivalent percentage by cement weight using equation (2), provided in the Spanish Instruction for Structural Concrete (Ministerio de Fomento, 2008). Furthermore, the initial chloride content was assumed to be equal to zero.

$$
C_{\%, \text { cem }}(x, t)=\frac{C_{\%, \text { conc }}(x, t) \cdot 2300}{C e m}
$$

The different chloride profiles obtained for each element and side are shown in figure 3, as well as the experimental data curves fitted to equation (1). Some of the points were identified as outliers and were not considered in the analysis. The first outliers present in the profiles were the surface points in most of the samples. The chloride content at the surface of the samples was usually affected by several phenomena such as carbonation, washing out, and composition differences (Ann et al., 2009; de Vera et al., 2014). Therefore, the first points of the chloride profiles were not considered in the analysis, as recommended by the standards (Nordic Innovation, 1995). Furthermore, some of the samples showed the presence of humps in their chloride profiles at larger depths. Although the presence of these humps may be related to several phenomena, the most feasible are the presence of wetting-drying cycles (de Vera et al., 2014) and the precipitation of Friedel's salt (Baroghel-Bouny et al., 2009). The humps observed at larger depths in samples 6SI and 6SE may be related to the presence of wetting-drying cycles, because this phenomenon allows the chloride content to increase because of water absorption. For estimation porpoises, these data were considered as outliers and not taken into account in the analysis. Furthermore, samples from similar structural elements were considered to correspond to the same type of concrete. The model parameters obtained from the analysis are listed in table 4. 
The data shown in figure 3 and listed in table 4 give evidence of different exposure conditions, as indicated by the value of $C_{s}$. Such variations may be related to different environmental conditions (predominant winds or structure orientation). This situation is clearly seen in sample 3SE, where the influence of the wind direction is obvious. Furthermore, the data in table 4 show a pattern in the variation of the apparent chloride diffusion coefficient $D$, distinguishing two different exposure zones in the cooling tower:

- Exposure zone 1-E1: related to the external parts of all the samples (excluding sample 3SE, because of its particular exposure condition), as well as the internal parts of the samples from module 1. The values for this exposure condition are $\bar{D}_{\mathrm{E} 1}=7.32 \cdot 10^{-12} \mathrm{~m}^{2} / \mathrm{s}$ and $\bar{C}_{\mathrm{s}, \mathrm{E} 1}=2.9 \%$.

- Exposure zone 2-E2: related to the internal parts of the samples from module 2. The values for this exposure condition are $\bar{D}_{\mathrm{E} 2}=36.1 \cdot 10^{-12} \mathrm{~m}^{2} / \mathrm{s}$ and $\overline{\mathrm{S}}_{\mathrm{s}, \mathrm{E} 2}=1.8 \%$.

The data obtained from the experimental analysis were compared with the $D$ and $C s$ values reported in the literature (see table 5); these data correspond to the structures of ordinary Portland cement (OPC) concretes with water-to-binder (w/b) ratios ranging from 0.4 to 0.6 . The experimental values obtained for exposure condition E1 were in good agreement with the data corresponding to aerated conditions in the literature, as well as to values reported in the literature for precast concrete (Hooton and Titherington, 2004). Furthermore, similar values for $D$ are provided in the Spanish Code for Structural Concrete for concretes made with CEM I and a w/b ratio of 0.45 (Ministerio de Fomento, 2008). Moreover, assuming that all the elements were fabricated under similar conditions and with the same mix ingredients and dosage, the different values obtained for $D$ must be attributed to differences in the exposure conditions. Three possible phenomena can explain these variations: leaching effects, temperature variations, and the presence of wetting-drying cycles. 
The presence of a leaching phenomenon for either calcium or hydroxide ions may explain the differences between exposure zones E1 and E2. Nevertheless, the $\mathrm{pH}$ of the water in the cooling system was close to a value of six, thus excluding an accelerated calcium leaching process. Considering the leaching of $\mathrm{OH}^{-}$ions, the neutral $\mathrm{pH}$ value of the cooling water could result in a drastic $\mathrm{pH}$ reduction of the concrete in the surface layer from 13 to 6 , which would lead to a reduction in the chloride binding capacity. However, because the cooling water is the same throughout the structure, this leaching phenomenon would be generalized and cannot explain the differences observed in the value of $D$.

The temperature could also have a strong effect on the diffusion coefficient. The mean environmental temperature at the location of the cooling tower is about $17^{\circ} \mathrm{C}$. In addition, the water in the cooling tower is normally between $22.3^{\circ} \mathrm{C}$ and $36.2^{\circ} \mathrm{C}$, with an average service temperature of $33^{\circ} \mathrm{C}$. The influence of the temperature on $D$ can be assessed by adopting the Arrhenius equation, described by equation (3). In this equation, $D_{T}$ is the diffusion coefficient $\left(\mathrm{m}^{2} / \mathrm{s}\right)$ for each temperature $T(\mathrm{~K}), D_{294 \mathrm{~K}}$ is the diffusion coefficient at the normal temperature $\left(5.9 \times 10^{-12} \mathrm{~m}^{2} / \mathrm{s}\right)$, and $E_{a}$ is the activation energy for chloride diffusion ( $\left.40 \mathrm{~kJ} / \mathrm{mol}\right)$. Thus, the effect of the temperature on $D$ can be analyzed for the exposure conditions by applying equation (3).

$$
D_{T}=D_{294 \mathrm{~K}} \cdot \frac{T}{294} \cdot \exp \left[-\frac{E_{a}}{R}\left(\frac{1}{T}-\frac{1}{294}\right)\right]
$$

The service temperature may have a marked effect on the variation of $D$ (see figure 4). However, an average service temperature higher than $40^{\circ} \mathrm{C}$ is needed to justify the differences observed between the exposure zones (E1 and E2). Furthermore, the effect of the temperature must be the same for all the rooms of the cooling tower, and thus may increase the value of $D$ in all the elements. 
Therefore, the presence of wetting-drying cycles inside the cooling tower will be considered. Wetting-drying cycles can accelerate chloride penetration because capillary suction increases the penetration of chloride ions (Hong and Hooton, 1999; Marchand and Samson, 2009). Likewise, the effects increase as long as the wetting-drying cycles exist. The power station has 12 technical stopovers programmed throughout the year, each one lasting 4 or 5 days. During these stopovers, the cooling systems are still operating, with the exception of the rooms orientated to the company offices. The cooling systems in the rooms with a south-southeast orientation are shut down during these periods in order to prevent the corrosion of the metallic structures in the offices, thus producing several wetting-drying cycles in these rooms.

\section{Safety assessment of structure}

The corrosion of the steel rebar leads to a reduction in the structural response of the affected concrete sections, mainly due to decreases in the mechanical properties of the steel. These aspects must be considered when assessing the global safety of the structural elements. In this research, structural and sectional analyses following the criteria suggested in the Model Code (fib, 2010) were performed. The main aim was to analyze the mechanical response of the structural elements considering different levels of material damage. Therefore, the maximum steel section losses were determined to meet the requirements for the service limit state (SLS) and ultimate limit state (ULS).

The representative elements considered in the structural analysis were the main and roof girders previously described. The design bending and shear laws for both girders were obtained using the SAP2000® software, considering their support conditions and the service loads gathered in the project. The most unfavorable sections were analyzed, and a global safety coefficient $F_{\mathrm{s}}$ was derived as a function of time, considering different damage levels due to 
reinforcement corrosion. The $F_{S}$ value was obtained by dividing the ultimate capacity of the section (ultimate bending moment $M_{u}$, for instance) by the design external load (design bending moment, $\left.M_{d}\right)$.

\section{Sectional analysis strategy}

The sectional analysis was performed using the results of the analysis of the evolutionary sections (AES) model previously published in the literature (de la Fuente et al., 2012). The AES model is capable of modeling the non-linear responses of sections made of different materials (concrete, steel, and fibers). This model was used to determine the ultimate bending moment capacity $\left(M_{u}\right)$, stress-strain state of the constitutive materials, and damage due to the reinforcement corrosion in the studied cross sections under service conditions.

In this model, the internal stresses are integrated using a sectional discretization that considers area elements $(d A c)$ with a constant thickness for the concrete and concentrated area elements to simulate the steel rebars (see figure 5a). Constitutive equations are defined for each of the materials to simulate its uniaxial behavior under a defined load state $(N, M)$. The concrete's compressive response is modeled using the law proposed in MC-2010 (see figure 5b). In addition, the uniaxial behavior of the plain steel reinforcing is modeled using a bi-linear constitutive equation with perfect hardening (see figure 5c), whereas the prestressing steel reinforcement is modeled using the Ramberg-Osgood law.

The damage in the plain steel reinforcement due to corrosion was modeled by the reduction in the cross section of the bars, as well as the reduction in its yielding strength $f_{y}$, using equation (4), as suggested by Muñoz (Muñoz, 2009). Equation (4) relates the relative loss of $f_{y}\left(\Delta f_{y, \Delta \Phi)}\right.$ to the cross-sectional loss of the bar $(\Delta \Phi)$ expressed in micrometers.

$$
\Delta f_{y, \Delta \Phi}=0.217 \cdot \Delta \Phi^{0.6115}
$$


The model was calibrated using the experimental results published in the literature (Almusallam, 2001; Apostolopoulos et al., 2005; Chen et al., 2005) for the elastic limit reduction in reinforced steel with different compositions, manufacturing processes, and exposure conditions. The main hypotheses considered in the modeling of the sectional behavior were as follows:

- There is perfect adherence between the materials.

- Plane sections remain plane after load application.

- Distortion due to shear is neglected.

The assumption of perfect adherence might be debatable because other researchers (Coronelli and Gambarova, 2004) stated that corrosion could lead to a severe reduction in the bond-slip strength. Therefore, this reduction would be of major relevance in the case of the cracking SLS, and the failure of the anchorages (Sarveswaran et al., 2000; Plizzari et al., 1996); in both cases, the critical limit is the bond resistant mechanism. However, the structural elements that were analyzed showed the critical performance in terms of bending, which was analyzed at the sectional level. Hence, both the cross-sectional reduction of the reinforcement and the yielding strength of the steel were considered to simulate the corrosion process.

The $\boldsymbol{\sigma}-\boldsymbol{\varepsilon}$ state of a concrete cross section subjected to a couple of $N$ and $M$ design loads could be obtained after discretization by solving the non-linear system resulting from applying the equilibrium and compatibility conditions defined in equations (5) to (7). This system of equations is solved using a Newton-Raphson iterative method.

$$
\begin{gathered}
N=\iint_{A_{c}} \sigma_{c}\left(\varepsilon_{c}\right) \cdot d A_{c}+\sum_{i=1}^{n_{s}} \sigma_{s, i}\left(\varepsilon_{s, i}\right) \cdot A_{s, i} \\
M+N y_{c d g}=\iint_{A_{c}} \sigma_{c}\left(\varepsilon_{c}\right) \cdot y_{c} \cdot d A_{c}+\sum_{i=1}^{n_{s}} \sigma_{s, i}\left(\varepsilon_{s, i}\right) \cdot y_{s, i} \cdot A_{s, i}
\end{gathered}
$$




$$
\varepsilon_{c}\left(y_{c}\right)=\varepsilon_{0}+y_{c} \cdot \chi
$$

Finally, the considerations related to the structural safety and reliability, as well as the partial safety factors of both the loads and materials, were those defined in MC-2010 (fib, 2010).

\section{Reliability analysis}

Only the reliability analysis of the main girder is described in detail. The results obtained for the roof girder are provided to assess the global reliability of the structure.

\section{Description}

The reinforcement arrangement for the element is presented in figure 6a. The main longitudinal reinforcement configuration is the mechanical minimum, to guarantee the ductile behavior in the case of a failure due to bending. The reinforcement is placed at the bottom of the cross section, and consists of 2 bars with a diameter of $25 \mathrm{~mm}\left(\Phi_{25}\right)$ and 2 bars with a diameter of $32 \mathrm{~mm}$ $\left(\Phi_{32}\right)$. The upper longitudinal reinforcement $\left(2 \Phi_{25}\right)$ is not considered in this analysis, because this reinforcement was used for construction purposes. Similarly, the number of shear stirrups was also designed to avoid a shear brittle failure.

The main girder is simply supported at its edges and is only subjected to dead loads during service operations. Thus, the loads are as follows: $(1)$ the self-weight of the girder $\left(\mathrm{G}_{\mathrm{k}, 1}=\right.$ $4.84 \mathrm{kN} / \mathrm{m})$, (2) self-weight of the eight intermediate beams resting on the main girder $\left(\mathrm{G}_{\mathrm{k}, 2}=\right.$ 4.06 kN), and (3) PVC filling load acting on the intermediate beams and transmitted to the main girder $\left(G_{k, 3}=7.67 \mathrm{kN}\right) . G_{k, 2}$ and $G_{k, 3}$ are simulated as point loads acting on the supports of each

of the eight intermediate beams. A partial safety coefficient $\gamma_{G}$ equal to 3.5 was considered to obtain the design values of all the loads and the strength distribution, because the actions described are permanent and constant.

The results presented in figure 6 highlight that the maximum design bending moment (145.0 
$\mathrm{kNm}$ ) is reduced compared to the dimensions of the cross section and placed reinforcement (ultimate resistant bending moment $M_{u}=627.0 \mathrm{kNm}$ for the midspan section).

\section{Response under bending moment}

The response of the most unfavorable cross section subjected to bending moments was calculated using the AES model, considering the effect of reinforcement corrosion. The corrosion of the plain steel reinforcement was simulated as a range of nominal diameter reductions of the bars $(\Delta \Phi)$. Each reduction resulted in a residual steel section $\left(A_{s, \Delta \Phi}\right)$ as defined by equation (8). Thus, the relative steel section loss $\left(\Delta A_{s, r e l}\right)$ related to the initially undamaged steel reinforcement section $\left(A_{s, o}\right)$ can be calculated using equation (9)

$$
\begin{gathered}
A_{s, \Delta \Phi}=\frac{\pi}{4}\left[\left(\Phi_{32}-\Delta \Phi\right)^{2}+\left(\Phi_{25}-\Delta \Phi\right)^{2}\right] \\
\Delta A_{s, r e l}=\frac{\Delta_{s, 0}-\Delta_{s, \Delta \Phi}}{\Delta_{s, 0}}=\frac{2 \cdot \Delta \Phi^{2} \cdot\left(\frac{\Phi_{32}+\Phi_{25}}{\Delta \Phi}-1\right)}{\Phi_{32}^{2}+\Phi_{25}^{2}}
\end{gathered}
$$

As can be noticed, the corrosion damage is considered to be identical for all the bars through parameter $\Delta \Phi$. This assumption is on the safe side because the section loss should be lower for bars with a larger diameter $\left(\Phi_{32}\right)$. The steel section loss due to corrosion also produces reductions in the mechanical properties, the most important being the one that affects $f_{y}$. The relative loss in the characteristic value of $f_{y}\left(\Delta f_{y k, \Delta \Phi}\right.$, see equation 4) with $\Delta A_{s, \Delta \Phi}$ is shown in figure 7 . The results obtained from the sectional analysis with the AES model are listed in table 6 . The variables used in this analysis are shown in figure 5. Moreover, $\sigma_{s}$ and $\varepsilon_{s}$ are the tension stress and strain of the main longitudinal reinforcement, respectively. Finally, $\varepsilon_{c}$ is the strain of the most compressed concrete layer.

The global safety factor $\left(F_{s}\right)$ is defined as the ratio between the ultimate resistant bending moment of the section $M_{u}$, which varies depending on the damage level, and the design moment 
$M_{d}(145.0 \mathrm{kNm}$ for the most unfavorable cross section, see figure 6). It must be emphasized that $F_{s}$ is not strictly a safety factor, but a safety margin for the girder when facing normal loads in the ULS. Values of $F_{s}>1$ indicate an excess amount of reinforcing steel in the structural element (over-reinforced), and values of $F_{s}<1$ indicate an unsafe situation for the structure (underreinforced). The obtained results showed that the main girder was over-reinforced, because the value of $F_{s}$ was 4.3 in the case of the full integrity of the cross section. In this hypothetical situation, the failure of the cross section would be ductile $\left(\varepsilon_{s}=5.0 \mathrm{~mm} / \mathrm{m}>\varepsilon_{y d}=f_{y k} /\left(\gamma_{s}{ }^{*} E_{s}\right)=\right.$ $500 /(1.15 * 200000)=2.17 \mathrm{~mm} / \mathrm{m})$ due to the excessive compression strain of the concrete $\left(\varepsilon_{c}=\right.$ $\left.\varepsilon_{\text {cu }}=-3.5 \mathrm{~mm} / \mathrm{m}\right)$.

However, corrosion may even affect the failure mode, which can vary from the failure of the concrete $\left(\varepsilon_{c}=-3.5 \%\right)$ for values of $\Delta A_{s, \Delta \Phi}$ smaller than $13.3 \%$, to an excessive steel tension strain mode $\left(\varepsilon_{s}=10.0 \mathrm{~mm} / \mathrm{m}\right)$ for larger values of $\Delta A_{s, \Delta \Phi}$. Values of $\Delta A_{s, \Delta \Phi}$ close to $50 \%$ are needed to reduce $F_{s}$ to unity $\left(M_{d}=M_{u}\right)$, as can be seen in figure 8 . It should be taken into account that the analysis assumed perfect adherence between the steel and concrete. This hypothesis can be adopted until certain corrosion levels are achieved. The value of $\Delta A_{s, \Delta \Phi}$ that produces a relevant loss of adherence between the steel and concrete mainly depends on the confinement. In the literature, $20 \%$ is reported as a common value for $\Delta A_{s, \Delta \Phi}$ to produce a loss of adherence (as a safe-side consideration). In this analysis, this value was related to an $F_{s}$ value that was slightly larger than 2.5.

\section{Response under shear forces}

The shear forces expected to appear are minor given the transversal section dimensions (see figure 6). Assuming, on the safe side, that not all of the longitudinal plain steel reinforcement is effective, the minimum shear strength capacity of the cross section, $V_{u 2, \min }$, can be calculated 
according to equation (10), provided by the Spanish Instruction for Structural Concrete (Ministerio de Fomento, 2008). In this equation, $\gamma_{c}$ is the partial safety coefficient of concrete for the ULS (1.5), $\xi$ is a shape factor (1.641), $f_{c v}$ is the effective shear strength of the concrete $f_{c v}=f_{c k}$ $=35 \mathrm{~N} / \mathrm{mm}^{2}, \sigma_{c d}^{\prime}$ is the axial average stress in the gravity center of the cross section (which is equal to zero because there is neither an external compressive strain nor prestressing steel reinforcement), $b_{o}$ is the minimum width of the cross section (300 $\left.\mathrm{mm}\right)$, and $d_{s}$ is the nominal height (487 mm).

$$
V_{u 2, \min }=\left(\frac{0.075}{\gamma_{c}} \cdot \xi^{3 / 2} \cdot f_{c v}^{1 / 2}+0.15 \cdot \sigma_{c d}^{\prime}\right) \cdot b_{0} \cdot d_{s}
$$

With these considerations, $V_{u 2, \min }=90.8 \mathrm{kN}$, which is larger than the design effective shear load (71.7 kN, see figure $6 \mathrm{~b}$ ). Thus, the concrete cross section can resist the design shear load with no need for additional transversal reinforcement, using the minimum amount required to avoid fragile shear failure. Such a minimum reinforcement can be calculated using equation (11), where $f_{c t m}$ is the average tensile strength of the concrete, which can be considered to be $0.3 \cdot \sqrt[3]{f_{c k}}{ }^{2}$ and therefore $3.2 \mathrm{~N} / \mathrm{mm}^{2}$ (Ministerio de Fomento, 2008).

$$
A_{s t, \min }=\frac{f_{c t m}}{7.5 \cdot f_{y d}} \cdot b_{0}
$$

The value of $f_{y d}$ may change as a consequence of the reinforcement section loss, which will increase $A_{s t, m i n}$. Thus, this $A_{s t, m i n}$ is a function of $\Delta \Phi\left(A_{s t, m i n, \Delta \Phi}\right)$, and can be calculated using equations 11 and 4 . Such an evaluation shall be performed by solving the non-linear equation $A_{s t, \Delta \Phi} \leq A_{s t, m i n, \Delta \Phi}$. In this case, $A_{s t, \Delta \Phi}$ is calculated using equation (12). The results of the calculus are listed in table 7.

$$
A_{s t, \Delta \Phi}=3 \pi \cdot\left[\left(\Phi_{6}-\Delta \Phi\right)^{2}+\left(\Phi_{8}-\Delta \Phi\right)^{2}\right]
$$


The value of $A_{s t, m i n, \Delta \Phi}$ increases with the damage level of the reinforcement, as seen in figure 9. A $\Delta A_{s t, \Delta \Phi}$ value of $63 \%$ is needed to contradict the requirement for ductile failure in the ULS. Nevertheless, a maximum $\Delta A_{s t, \Delta \Phi}$ value of $30 \%$ is utilized during the service life of the structure, because the adherence between the steel and concrete cannot be ensured for larger values. Similar results were obtained in the reliability analysis of the roof girder. This element is described in figure 10, along with the design bending moments and shear forces. Because the roof girder is a prestressed concrete element, no corrosion is allowed, and no damage can be considered. The calculus is a classic verification problem. The total long-term loss of the prestressing force is $15 \%$ of $P_{0}$, the value of $M_{u}$ is $482.2 \mathrm{kNm}$, and the global safety factor is

2.38. Therefore, for normal loads under the ULS, the roof girder is over-reinforced. Furthermore, the cracking moment was calculated to determine whether the critical cross section exceeded the ultimate loosening state. Considering the exposure conditions, the decompression risk was small, because $M_{\text {fis }} \approx 2 M_{k}$.

\section{Durability assessment and remaining service life estimation}

The remaining service life of the structure was assessed based on the results of the analysis of the chloride penetration profiles and safety assessment of the structure. First, the ability of the structure to reach the design service life was analyzed considering the chloride-ion penetration in the absence of wetting-drying cycles. Second, the remaining service life of the structure was estimated considering the effect of wetting-drying cycles. This durability assessment considered the hypotheses listed below, along with the main parameters listed in table 8.

- Exposure zone E1 is representative of the structure commissioning, except for the prestressedreinforced elements. The estimation of $D_{0}$ was performed using equation (13), which was proposed by Visser (Visser et al., 2002). $D_{0}$ is the apparent chloride diffusion coefficient $\left(\mathrm{m}^{2} / \mathrm{s}\right)$ 
of the concrete at the time the structure was commissioned $t_{0}$ (6 months), $D_{t}$ is the apparent chloride diffusion coefficient $\left(\mathrm{m}^{2} / \mathrm{s}\right)$ at the exposure time $t$ (18.5 months), and $n$ is a concrete age factor (0.23; DuraCrete, 2000). The value obtained for $D_{0}$ is $7.32 \times 10^{-12} \mathrm{~m}^{2} / \mathrm{s}$.

$$
D_{0}=D_{t} \cdot(1-n) \cdot\left(\frac{t}{t_{0}}\right)^{n}
$$

- Exposure zone E2 accounts for the effect of wetting-drying cycles in the precast concrete elements, except for the prestressed-reinforced elements.

- Since no experimental data are available for the prestressed-reinforced elements, data from the literature was used to estimate $D_{0}$. For that, values obtained in elements with characteristics and exposure conditions similar to the ones found in the case study were considered. Based on the work of Tanaka et al (2006) and O’Connor and Kenshel (2013) $D_{0}$ was assumed as $0.3 \times 10^{-12}$ $\mathrm{m}^{2} / \mathrm{s}$.

- Likewise, the effect of wetting-drying cycles on the prestressed-reinforced concrete elements was considered using a multiplication factor of 4.932, which was obtained from the experimental data. Thus, a value for $D$ of $1.48 \times 10^{-12} \mathrm{~m}^{2} / \mathrm{s}$ was derived.

Table 8. Parameters used for durability assessment and remaining service-life estimation The approach of Tuutti (Tuutti, 1982) was used to estimate the service life of the elements, $t_{l}$, considering the initiation time $t_{i}$ and propagation time $t_{p}$ as expressed in equation (14). Furthermore, the ultimate service lifetime was estimated using equation (15), considering the time to failure of the structural element.

$$
\begin{aligned}
& t_{l}=t_{i}+t_{p} \\
& t_{u}=t_{l}+t_{f}
\end{aligned}
$$

The time required for the chloride-ions to reach the amount needed at the reinforcement surface 
to initiate corrosion, $t_{i}$, can be defined by equation (16), as presented in the Spanish Code for Structural Concrete (Ministerio de Fomento, 2008). The threshold chloride content $\left(C_{t h}\right.$, as a percentage of the cement weight) varies depending on the exposure condition and type of structural element, as listed in table 8 . The values considered were those provided by the Spanish Code for Structural Concrete (Ministerio de Fomento, 2008).

$$
t_{i}=\left(\frac{d}{56157 \cdot \sqrt{12 \cdot D} \cdot\left(1-\sqrt{\frac{C_{t h}-C_{0}}{C_{s}-C_{0}}}\right)}\right)^{2}
$$

Once a sufficient amount of chloride ions reaches the steel surface, the propagation of the corrosion starts. The formulation described by Siemes et al. (Siemes et al., 1985) was used to estimate the propagation time $t_{p}$. Equation (17) defines $t_{p}$ in relation to a critical loss of section $\Delta \Phi_{c}$ (micrometers) and corrosion velocity $V_{c o r r}$ (micrometers/year). Although many different models are available in the literature to estimate this value, this formulation was chosen because of its straightforwardness for structural engineers.

$$
t_{p}=\frac{\Delta \Phi_{c}}{V_{\text {corr }}}
$$

The value of $\Delta \Phi_{c}$ was calculated using equation (18), assuming a uniform corrosion process (to be on the safe side) and considering the work of Siemes et al. (Siemes et al., 1985):

$$
\Delta \Phi_{c}=80 \frac{d}{\Phi}
$$

Hence, the propagation time can be calculated using equation (19), which was obtained by combining equation (17) and equation (18).

$$
t_{p}=\frac{80 \cdot d}{V_{c o r r} \cdot \phi}
$$


The formulation presented in equation (19) requires the measurement or estimation of the steel corrosion velocity $V_{\text {corr }}$. The inspection of the structure in 2009 also involved the measurement of steel corrosion rates. These measurements were made at the outer side of the external walls using a GECOR 6 corrosimeter. The measured value of $i_{\text {corr }}$ was $4.40 \mu \mathrm{m} / \mathrm{cm}^{2}$, which indicated a high corrosion state (Otieno et al., 2012). This measurement was carefully considered in relation to the following:

- First, corrosion rate measurements are strongly dependent on environmental conditions. Because the field measurements were made on the external sides of the closure panels, they were not representative of the structural elements located in the internal part of the structure.

- Second, corrosion rate measurements are punctual measurements and can be affected by variability and many uncertainties, as pointed out by Otieno et al. (Otieno et al., 2012). They reported differences between the results of three $i_{\text {corr }}$ assessment techniques (gravimetric, 3LP, and GECOR) larger than an order of magnitude.

- Last, but not least, $i_{\text {corr }}$ must be converted to corrosion velocity values using a corrosion model, which can be either a uniform and constant corrosion rate or localized or non-uniform corrosion. Because the aim of this work was to determine the real effect of the wetting-drying cycles in the structure, the estimations were made using the values of $V_{\text {corr }}$ presented in the literature. We used the values provided for $V_{\text {corr }}$ by Sarja and Vesikari (Sarja and Vesikari, 1996). They considered values varying from $35 \mu \mathrm{m} /$ year to $122 \mu \mathrm{m} /$ year based on exposure conditions XS1 and XS3, respectively. These values are considered in most of the current structural codes, specifically the Spanish one (Ministerio de Fomento, 2008).

Last, the failure time of the structure was estimated based on the results of the structural analysis presented in section 4 . The failure time $t_{f}$ was calculated using equation (20), where $P_{\max }$ 
(micrometers) is the maximum corrosion depth, and $V_{\text {corr,f }}$ is the corrosion velocity at cracks. $P_{\max }$ can be estimated using equation (21), considering the value of $\Delta A_{s, \text { rel }}$ provided by the structural analysis (0.2).

$$
\begin{gathered}
t_{f}=\frac{P_{\max }}{2 \cdot V_{\text {corr }}} \\
P_{\max }=\frac{\phi \cdot\left(1-\sqrt{1-\Delta A_{s}}\right)}{2 \cdot 10^{-3}}
\end{gathered}
$$

Once the propagation time has passed, cracks will appear in the concrete element. Therefore, a

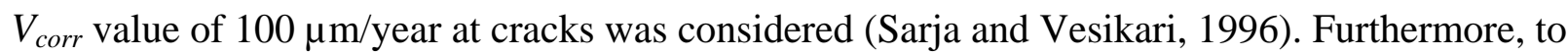
verify the suitability of the durability design of the structure, the chloride diffusion coefficient required to reach the designed service life was estimated using equation (22), which could be obtained using equation (16) and replacing $t_{i}$ with the service life of the element and subtracting the propagation period described by equation (19).

$$
D_{\text {calc }}=\frac{d^{2}}{12 \cdot\left(25-\left(\frac{80 \cdot d}{V_{\text {corr }} \cdot \phi}\right)\right) \cdot\left(56157 \cdot\left(1-\sqrt{\frac{C_{\text {th }}-C_{0}}{C_{s}-C_{0}}}\right)\right)^{2}}
$$

The durability estimations for the canal beam were performed using a value of $C_{t h}=0.6 \%$ and a value of $V_{\text {corr }}=122 \mu \mathrm{m} /$ year. The service life estimations considering the structure commissioning are shown in figure 11a. The results show that this element will never reach the design service life based on the initial design considerations. The different durability data obtained from the estimations are listed in table 9. The main factor affecting the service life of the element is the initiation time $t_{i}$, which is around 2 years. Such a low value for the initiation time demonstrates an inadequate durability consideration for this structural element. Because of the severe exposure conditions, the use of cement with pozzolanic additions should have been 
considered, as well as the use of protection systems for the concrete surface.

Furthermore, the service life of the element was halved because of the wetting-drying cycles (see figure 11b). All the estimations were in very good agreement with the experimental observations. Furthermore, the estimations made for the canal beam (see table 9) show that if no maintenance is given to the structural elements, the time to failure will be less than 10 years. To achieve the designed service life, a concrete with an apparent chloride diffusion coefficient of about $1 \cdot 10^{-13} \mathrm{~m}^{2} / \mathrm{s}$ should have been used. Such values for $D$ are related to high-performance concrete.

The durability estimations for the main girder were performed in a manner similar to those for the canal beam. The results obtained for the structure commissioning are shown in figure 12 . The variations are quite similar to those obtained for the canal beam, evidencing an inadequate durability consideration during the design of some of the elements of the structure. The data obtained from the durability estimations of the main girder are listed in table 10. The durability estimations for the roof girder were slightly different because of the active reinforcement. The exposure conditions were similar. However, a value of $C_{t h}=0.3 \%$ is taken into account because it is a prestressed element. The propagation stage was only considered for the passive reinforcement. The service life estimations are shown in figure 13. Even if an element can reach the design service life, the effect of the wetting-drying cycles should be considered, because these cause a huge reduction in the service life. The data obtained from the durability estimations of the main girder are listed in table 11. Furthermore, the passive reinforcement may be affected by corrosion. The propagation of corrosion may enable the appearance of cracks in the element, thus accelerating the ingress of chloride ions to the active reinforcement. 
The durability assessment presented above clearly reflects the effect of the wetting-drying cycles in the service life of the structure. The results presented for all the elements studied have shown that the wetting-drying cycles reduce the estimated service life since they accelerate the chloride penetration, diminishing mainly the initiation period. The wetting-drying cycles mainly affect to the initiation period, since allow the entrance of a larger amount of chlorides by water absorption. The service life of all the elements is reduced, the by a factor related with the depending on the type of element. For instance, the reduction in the precast reinforced element varies from a factor of 2 to 1.34, depending on the type of steel bar considered. This situation is more dramatic for the prestressed precast reinforced elements, which present presenting a reduction factor in their service life around 4.7.

\section{Concluding remarks}

The analysis of the degradation of the structure showed a preferential orientation in the degradation of the elements. The damages were higher in the part of the structure with a southsoutheast orientation, where the company offices are located. The operating conditions in the south-southeast part of the cooling tower were different, favoring the appearance of wettingdrying cycles. The chloride diffusion coefficients obtained from drilled core samples extracted at these locations were three times larger than the ones obtained at other locations. These results showed the marked effect of wetting-drying cycles on the chloride ion penetration, justifying the accelerated degradation phenomena observed in the structure.

The results obtained highlight that a consideration of the durability is mandatory for elements subjected to severe exposure conditions. As shown here, the use of simplified models could contribute to the early detection of problems and to a better design, despite the assumptions made in the simulation of the degradation process. 
The structural safety assessments for the main structural elements-the main girder and roof girder-showed that these elements are over-reinforced. The global safety coefficients obtained for the loads considered were 2.55 and 2.38, respectively. The results of the analyses showed that the corrosion of the passive reinforcement was related to huge reductions in the global safety parameter $F_{s}$. The structural study fixed the maximum loss of a reinforcement section at $20 \%$, to avoid a significant reduction in the global safety coefficient.

The service life was estimated based on the results of both the structural analysis and chloride ion penetration analysis. The results of our study showed that most of the structural elements would not have reached the design service life of 25 years. Furthermore, the presence of wetting-drying cycles worsens this situation. The ultimate service life of the elements is 6-10 years for the precast reinforced concrete elements and around 20 years for the passive reinforcement of the prestressed elements. These results give evidence of an inadequate durability strategy because the precast concrete elements were not able to withstand the prevailing exposure conditions.

\section{Acknowledgements}

The authors wish to thank the company that owns the thermal power station for providing access to the installations and all the information. Dr. I. Segura is supported by the postdoctoral Juan de la Cierva programme of the Spanish Ministry of Economy and Competitiveness.

\section{References}

AENOR-Spanish Association for Normalization (2009) UNE-EN 12390-8:2009 Testing hardened concrete-Part 8: Depth of penetration of water under pressure. AENOR, Madrid. Spain. 
Akgüll, F., and Frangopol, D. M. (2004) Lifetime performance analysis of existing prestressed concrete bridge superstructures. Journal of Structural Engineering, 130, 1889-1903.

Almusallam, A. A. (2001) Effect of degree of corrosion on the properties of reinforcing steel bars. Construction and Building Materials, 15 (8), 361-368.

Ann, K. Y., Ahn, J. H., and Ryou, J. S. (2009). The importance of chloride content at the concrete surface in assessing the time to corrosion of steel in concrete structures. Construction and Building Materials, 23 (1), 239-245.

Apostolopoulos, C. A., Papalopoulos, M. P., and Pantelakis, S. P. (2005) Tensile behaviour of corroded reinforcing steel bars BSt 500S. Construction and Building Materials, 20 (9), 782-789.

Baroghel-Bouny, V., Nguyen, T. Q., and Danglab, P. (2009) Assessment and prediction of RC structure service life by means of durability indicators and physical/chemical models. Cement and Concrete Composites, 31, 522-534.

Chen, Y. Y., Tzeng, H. J., Wei, L. I., and Shih, H. C. (2005). Mechanical properties and corrosion resistance of low-alloy steels in atmospheric conditions containing chloride. Materials Science and Engineering, 398 (1-2), 47-59.

Coronelli, D., and Gambarova, P. (2004). Structural assessment of corroded reinforced concrete beams: Modelling guidelines. Journal of Structural Engineering, 130 (8), 1214-1224.

Costa, A., and Appleton, J. (2002) Case studies of concrete deterioration in a marine environment in Portugal. Cement and Concrete Composites, 24 (1), 169-179.

Crank, J. (1975). The Mathematics of Diffusion. Oxford: Clarendon-Press 
de la Fuente, A., Aguado, A., Molins, C., and Armengou, J. (2012). Numerical model for the analysis up to failure of precast concrete sections. Computers and Structures, 106-107, 105-114.

de Vera, G., Climent, M. A., Viqueira, E., Antón, C., and López, M. P. (2014) Chloride penetration prediction in concrete through an empirical model based on constant flux diffusion. Journal of Materials in Civil Engineering, 10.1061/(ASCE)MT.19435533.0001173, 04014231.

DuraCrete-Final Technical Report. (2000). General Guidelines for Durability Design and Redesign. The European Union-Brite Euram III.

Funahashi, M. (1990) Predicting corrosion free service life of a concrete structure in a chloride environment. ACI Materials Journal, 87, 581-587.

Hong, K., and Hooton, R. D. (1999). Effects of cyclic chloride exposure on penetration of concrete cover. Cement and Concrete Research, 29, 1379-1386.

Hooton, R. D., and Titherington, M. P. (2004). Chloride resistance of high-performance concretes subjected to accelerated curing. Cement and Concrete Research, 34 (9), 15611567.

International Federation for Structural Concrete-fib (2010). Model Code 2010. Lausanne: International Federation for Structural Concrete. 2010.

Kudoh, K., Hirotani, A., Moriwake, A., and Yasuda, M. (1991) Study on durability of a repaired concrete structure in Tokyo bay. In: Evaluation and rehabilitation of concrete structures and innovations in design. ACI 128. 1293-1307. Hong Kong: ACI. 
Liam, K. C., Roy, S. K., and Northwood, D. O. (1992) Chloride ingress measurements and corrosion potential mapping study of a 24-year-old reinforced concrete jetty structure in a tropical marine environment. Magazine of Concrete Research, 44, 205-215.

Marchand, J., and Samson, E. (2009). Predicting the service-life of concrete structuresLimitations of simplified models. Cement and Concrete Composites, 31, 515-521.

Medeiros, M. H. F., Gobbi, A., Réus, G. C., and Helene P. (2013) Reinforced concrete in marine environment: Effect of wetting and drying cycles, height and positioning in relation to the seashore. Construction and Building Materials, 44, 452-457.

Melchers, R. E., and Li, C. Q. (2009). Reinforcement corrosion initiation and activation times in concrete structures exposed to severe marine environments. Cement and Concrete Research, 39 (11), 1068-1076.

Ministerio de Fomento. (1998) Spanish Code for Structural Concrete-EHE-98. Ministerio de Fomento, Madrid. Spain (in Spanish).

Ministerio de Fomento. (2008) Spanish Code for Structural Concrete-EHE-08. Ministerio de Fomento, Madrid. Spain (in Spanish).

Morinaga, S. (1992) Life prediction of reinforced concrete structure in hot and salt-laden environments. In: Concrete in Hot Climates. 155-164. E\&FN SPON.

Muñoz, A. (2009). Behavior of hyperstatic reinforced concrete beams corroded and repaired with mortar. Loss of mechanical properties in the steel reinforcement and cracking of concrete cover due to the corrosion process. PhD Thesis. Defended at the School of Civil Engineering of Madrid. Madrid, Spain (in Spanish).

Nordic Innovation (1995) Concrete, hardened: Accelerated chloride penetration (NT BUILD 443). Oslo: Nordic Innovation. 
O’Connor, A. J., and Kenshel, O. (2013) Experimental evaluation of the scale of fluctuation for spatial variability modeling of chloride-induced reinforced concrete corrosion. Journal of Bridge Engineering, 18, 3-14.

Otieno, M., Beushausen, H., and Alexander, M. (2012) Prediction of corrosion rate in reinforced concrete structures-a critical review and preliminary results. Materials and Corrosion, 63, 777-790.

Papé, T. M., and Melchers, R. E. (2011) The effects of corrosion on 45-year-old pre-stressed concrete bridge beams. Structure and Infrastructure Engineering, 7 (1-2), 101-108.

Peterman R. J., Ramirez J. A., and Poston, R. W. (1999) Durability assessment of bridges with full-span prestressed concrete form panels. ACI Materials Journal, 96, 11-19.

Plizzari, G. A., Marchina, E., and Giuriani, E. (1996). Experimental study of splitting and flexural cracks in an R/C beam with overlapped splices. Materials and Structures, 29, $19-27$.

Sarja, A., and Vesikari, E. (1996). Durability models. pp 69 in Durability Design of Concrete Structures-RILEM report 14. London: E \& F Spon.

Sarveswaran, V., Roberts, M. B., and Ward, J. A. (2000). Reliability assessment of deteriorating reinforced concrete beams. Proceedings of the Institution of Civil Engineers-Structures and Buildings, 140 (3), 239-247.

Shekarchi, M., Moradi-Marani, F., and Pargar, F. (2011). Corrosion damage of a reinforced concrete jetty structure in the Persian Gulf: A case study. Structure and Infrastructure Engineering, 7 (9), 701-713.

Siemes, A. J. M., Vrouwenvelder, A. C. W. M., and van den Beukel, A. (1985). Durability of buildings: A reliability analysis. Heron 30 (3). 
Song, H-W., Lee, C-H., and Ann, K. Y. (2008) Factors influencing chloride transport in concrete structures exposed to marine environments. Cement and Concrete Composites, 30, 113121.

Tanaka, Y., Kawano, H., Watanabe, H., and Nakajo, T. (2006). Study on cover depth for prestressed concrete bridges in airborne-chloride environment. PCI Journal March-April, 42-53.

Tuutti, K. (1982). Corrosion of Steel in Concrete. Swedish Cement and Concrete Research Institute, Report No. 4. Stockholm: Swedish Cement and Concrete Research Institute.

Uji, K., Matsuoka, Y. and Maruya, T. (1990). Formation of an equation for surface chloride content of a concrete due to permeation of chloride. In: Corrosion of Reinforcement in Concrete, 258-267. London, UK: Elsevier Applied Science.

Visser, J. H. M., Gaal, G. C. M., and de Rooij, M. R. (2002). Time dependency of chloride diffusion coefficients in concrete. Published at the Third RILEM Workshop on Testing and Modelling the Chloride Ingress into Concrete, 421-431. Bagneux, France: RILEM.

\section{Tables}

Table 1. Concrete cover depth measurements

\begin{tabular}{|c|c|c|c|c|}
\hline \multirow{2}{*}{ Structural element } & \multicolumn{4}{|c|}{ Concrete cover depth (mm) } \\
\cline { 2 - 5 } & Inspection (2009) & Inspection (2012) \\
\cline { 2 - 5 } & Mean & Sd & Mean & Sd \\
\hline Canal beam & 45 & 10 & n.d. & n.d. \\
\hline Main girder & 34 & 12 & 59 & 3 \\
\hline Column & 40 & 7 & 40 & 3 \\
\hline Panel & 40 & 12 & 43 & 4 \\
\hline
\end{tabular}


Table 2. Main design characteristics of each structural element of case study

\begin{tabular}{|c|c|c|c|}
\hline Structural element & Concrete type & $\begin{array}{c}f_{c k} \\
(\mathrm{MPa})\end{array}$ & $\begin{array}{c}\text { Cover } \\
(\mathrm{mm})\end{array}$ \\
\cline { 1 - 3 } Canal beam & Reinforced & 35 & 40 \\
\cline { 1 - 2 } Main girder & & & \\
\cline { 1 - 2 } Roof girder & Prestressed & 50 & $80 / 40$ \\
\hline
\end{tabular}

Table 3. Compressive strength and water permeability measured in drilled cores from different structural elements

\begin{tabular}{|c|c|c|c|c|}
\hline \multirow[t]{2}{*}{ Structural element } & \multirow[t]{2}{*}{ Sample } & \multirow{2}{*}{$\begin{array}{l}\text { Compressive strength } \\
\left(\mathrm{N} / \mathrm{mm}^{2}\right)\end{array}$} & \multicolumn{2}{|c|}{$\begin{array}{l}\text { Depth of water penetration } \\
\text { (mm) }\end{array}$} \\
\hline & & & Mean & Max \\
\hline \multirow{4}{*}{ Canal beam } & $1 \mathrm{D}$ & n.d. & 0.6 & 1.3 \\
\hline & $1 S$ & n.d. & 2.6 & 3.9 \\
\hline & $2 S$ & 43.8 & \multicolumn{2}{|c|}{ n.d. } \\
\hline & $3 \mathrm{D}$ & 64.4 & \multicolumn{2}{|c|}{ n.d. } \\
\hline \multirow{4}{*}{ Panel } & $5 \mathrm{D}$ & n.d. & 1.5 & 2.1 \\
\hline & $6 \mathrm{D}$ & n.d. & 2.6 & 3.5 \\
\hline & $7 \mathrm{~S}$ & 66.9 & \multicolumn{2}{|c|}{ n.d. } \\
\hline & $8 S$ & 72.9 & \multicolumn{2}{|c|}{ n.d. } \\
\hline
\end{tabular}


Table 4. Parameters resulting from analysis of chloride penetration profiles

\begin{tabular}{|c|c|c|c|c|c|c|}
\hline \multirow{2}{*}{$\begin{array}{l}\text { Structural } \\
\text { element }\end{array}$} & \multicolumn{3}{|c|}{ Location } & \multirow{2}{*}{ Sample } & \multirow{2}{*}{$\left(\times 10^{-12} \mathrm{~m}^{2} / \mathrm{s}\right)$} & \multirow{2}{*}{$\begin{array}{c}C_{s} \\
\text { (\% cement wt) }\end{array}$} \\
\hline & Module & Room & Orientation & & & \\
\hline \multirow{4}{*}{$\begin{array}{l}\text { Canal } \\
\text { beam }\end{array}$} & \multirow{4}{*}{2} & \multirow{2}{*}{14} & \multirow{2}{*}{ SE } & 3SE & 22.23 & 0.735 \\
\hline & & & & $3 S I$ & 45.28 & 2.134 \\
\hline & & \multirow{2}{*}{16} & \multirow{2}{*}{ SW } & $4 \mathrm{DE}$ & 6.16 & 2.519 \\
\hline & & & & 4DI & 53.73 & 2.089 \\
\hline \multirow{8}{*}{ Panel } & \multirow{4}{*}{2} & \multirow{2}{*}{16} & \multirow{4}{*}{ SE } & $5 S E$ & 6.44 & 3.645 \\
\hline & & & & 5SI & 22.80 & 1.775 \\
\hline & & \multirow{2}{*}{16} & & $6 \mathrm{SE}$ & 9.55 & 3.375 \\
\hline & & & & $6 \mathrm{SI}$ & 36.46 & 1.584 \\
\hline & \multirow{4}{*}{1} & \multirow{2}{*}{1} & \multirow{4}{*}{ NW } & $7 \mathrm{DE}$ & 5.56 & 3.778 \\
\hline & & & & 7DI & 10.89 & 1.506 \\
\hline & & \multirow{2}{*}{1} & & $8 \mathrm{DE}$ & 6.07 & 3.327 \\
\hline & & & & 8DI & 6.71 & 3.803 \\
\hline
\end{tabular}

Table 5. Reported values of $D$ and $C_{s}$ of concrete structures exposed to marine environments, with all OPC concrete data based on w/b range of 0.4-0.6

\begin{tabular}{|c|c|c|c|c|}
\hline$C_{s}(\%$, cem. $)$ & $D\left(\times 10^{-12} \mathrm{~m}^{2} / \mathrm{s}\right)$ & Time (years) & Exposure & References \\
\hline $3.74-5.54$ & $3.52-4.66$ & 16 & Tidal/splash & (Funahashi, 1990) \\
\hline $0.433-2.22$ & \multirow{3}{*}{ Unknown } & \multirow{3}{*}{$23-58$} & Aerated & \multirow{3}{*}{ (Uji et al., 1990) } \\
\hline $0.83-5.23$ & & & Splash & \\
\hline 2.39-6.41 & & & Tidal & \\
\hline $1.5-3.10$ & 2.13-3.39 & 24 & Splash/tidal & (Liam et al., 1992) \\
\hline 1.97 & 3.5 & 20 & Splash/tidal & (Kudoh et al., 1991) \\
\hline $0.20-2.43$ & Unknown & 30 & Aerated & (Morinaga, 1992) \\
\hline $0.72-4.62$ & $1.28-5.53$ & \multirow{2}{*}{13} & Aerated & \multirow{2}{*}{ (de Vera et al., 2014) } \\
\hline 23.18 & 1.37 & & Splash & \\
\hline
\end{tabular}


Table 6. Mechanical parameters in ULS for normal loads obtained for different values of $\Delta \Phi$

\begin{tabular}{|c|c|c|c|c|c|c|c|c|c|}
\hline $\begin{array}{c}\Delta \Phi \\
(\mu \mathrm{m})\end{array}$ & $\begin{array}{c}\Delta A_{s . \Delta \Phi} \\
(\%)\end{array}$ & $\begin{array}{c}A_{s, \Delta \Phi} \\
\left(\mathrm{mm}^{2}\right)\end{array}$ & $\begin{array}{c}\Delta f_{y k, \Delta \Phi} \\
(\%)\end{array}$ & $\begin{array}{c}x_{n} \\
(\mathrm{~mm})\end{array}$ & $\begin{array}{c}\varepsilon_{s} \\
(\mathrm{~mm} / \mathrm{m})\end{array}$ & $\begin{array}{c}\varepsilon_{c} \\
(\mathrm{~mm} / \mathrm{m})\end{array}$ & $\begin{array}{c}\sigma_{s} \\
\left(\mathrm{~N} / \mathrm{mm}^{2}\right)\end{array}$ & $\begin{array}{c}M_{u} \\
(\mathrm{kNm})\end{array}$ & $F_{s}$ \\
\hline 0 & 0.0 & 2590 & 0.0 & 201 & 5.0 & -3.5 & 435 & 627 & 4.3 \\
\hline 1000 & 6.8 & 2414 & 14.8 & 160 & 7.2 & -3.5 & 370 & 513 & 3.5 \\
\hline 2000 & 13.3 & 2245 & 22.6 & 135 & 9.1 & -3.5 & 336 & 440 & 3.0 \\
\hline 3000 & 19.6 & 2081 & 29.0 & 115 & 10.0 & -3.1 & 309 & 380 & 2.6 \\
\hline 4000 & 25.7 & 1924 & 34.6 & 98 & 10.0 & -2.5 & 284 & 327 & 2.3 \\
\hline 5000 & 31.5 & 1773 & 39.7 & 83 & 10.0 & -2.1 & 262 & 281 & 1.9 \\
\hline 6000 & 37.1 & 1629 & 44.3 & 70 & 10.0 & -1.7 & 242 & 240 & 1.7 \\
\hline 7000 & 42,4 & 1491 & 48.7 & 59 & 10.0 & -1.4 & 223 & 204 & 1.4 \\
\hline 8000 & 47,5 & 1359 & 52.9 & 50 & 10.0 & -1.1 & 205 & 172 & 1.2 \\
\hline 9000 & 52.4 & 1233 & 56.8 & 41 & 10.0 & -0.9 & 188 & 144 & 1,0 \\
\hline
\end{tabular}

Table 7. Sectional parameters in ULS for tangential loads obtained for different values of $\Delta A_{\text {s.rel }}$

\begin{tabular}{|c|c|c|c|c|c|}
\hline $\begin{array}{c}\Delta \Phi \\
(\mathrm{mm})\end{array}$ & $\begin{array}{c}\mathrm{A}_{\text {st. } \Delta \Phi} \\
\left(\mathrm{mm}^{2} / \mathrm{m}\right)\end{array}$ & $\begin{array}{c}\Delta \mathrm{A}_{\text {st.rel }} \\
(\%)\end{array}$ & $\begin{array}{c}\Delta \mathrm{f}_{\text {yd.rel }} \\
(\%)\end{array}$ & $\begin{array}{c}\mathrm{f}_{\mathrm{yd}} \\
\left(\mathrm{N} / \mathrm{mm}^{2}\right)\end{array}$ & $\begin{array}{c}\mathrm{A}_{\text {st.min. } \Delta \Phi} \\
\left(\mathrm{mm}^{2} / \mathrm{m}\right)\end{array}$ \\
\hline 0 & 942 & 0.0 & 0.0 & 400 & 320 \\
\hline 1000 & 697 & 26.0 & 14.8 & 400 & 320 \\
\hline 2000 & 490 & 48.0 & 22.6 & 387 & 331 \\
\hline 3000 & 320 & 66.0 & 29.0 & 355 & 361 \\
\hline 4000 & 188 & 80.0 & 34.6 & 327 & 391 \\
\hline 5000 & 94 & 90.0 & 39.7 & 302 & 424 \\
\hline 6000 & 38 & 96.0 & 44.3 & 278 & 460 \\
\hline
\end{tabular}


Table 8. Parameters used for durability assessment and remaining service-life estimation

\begin{tabular}{|c|c|c|c|c|}
\hline Material & Hypothesis & $\begin{array}{c}D \\
\left(\times 10^{-12} \mathrm{~m}^{2} / \mathrm{s}\right)\end{array}$ & $\begin{array}{c}C_{s} \\
(\% \text { cement wt })\end{array}$ & $\begin{array}{c}C_{\text {th }} \\
(\% \text { cement wt })\end{array}$ \\
\hline \multirow{2}{*}{ RC } & Estimated at $t_{0}$ & 7.32 & & \multirow{2}{*}{2.6} \\
\cline { 2 - 3 } & Effect of wetting-drying cycles & 36.10 & \multirow{2}{*}{2.2} & \multirow{2}{*}{0.6} \\
\hline \multirow{2}{*}{ PC } & Estimated at $t_{0}$ & 0.3 & & 0.3 \\
\cline { 2 - 3 } & Effect of wetting-drying cycles & 1.48 & & \\
\hline
\end{tabular}

Table 9. Durability estimations for canal beam

\begin{tabular}{|c|c|c|c|c|c|c|c|}
\hline \multirow{2}{*}{ Exposure condition } & \multirow{2}{*}{$\phi(\mathrm{mm})$} & \multicolumn{5}{|c|}{ Service life estimations (years) } & \multirow{2}{*}{$\begin{array}{c}D_{\text {calc }} \\
\left(\times 10^{-12} \mathrm{~m}^{2} / \mathrm{s}\right)\end{array}$} \\
\hline & & $t_{i}$ & $t_{p}$ & $t_{l}$ & $t_{f}$ & $t_{u}$ & \\
\hline \multirow{4}{*}{ In-service } & 20 & \multirow{4}{*}{2.69} & 1.31 & 4.00 & 5.28 & 9.28 & 0.78 \\
\hline & 16 & & 1.64 & 4.33 & 4.22 & 8.55 & 0.79 \\
\hline & 12 & & 2.19 & 4.87 & 3.17 & 8.04 & 0.81 \\
\hline & 10 & & 2.62 & 5.31 & 2.64 & 7.95 & 0.83 \\
\hline \multirow{4}{*}{ Wetting-drying cycles } & 20 & \multirow{4}{*}{0.55} & 1.31 & 1.86 & 5.28 & 7.14 & 0.16 \\
\hline & 16 & & 1.64 & 2.19 & 4.22 & 6.41 & 0.16 \\
\hline & 12 & & 2.19 & 2.74 & 3.17 & 5.91 & 0.16 \\
\hline & 10 & & 2.62 & 3.17 & 2.64 & 5.81 & 0.17 \\
\hline
\end{tabular}


Table 10. Durability estimations for main girder

\begin{tabular}{|c|c|c|c|c|c|c|c|}
\hline \multirow{2}{*}{ Exposure condition } & \multirow{2}{*}{$\phi(\mathrm{mm})$} & \multicolumn{5}{|c|}{ Service life estimations (years) } & \multirow{2}{*}{$\left(\times 10^{-12} \mathrm{~m}^{2} / \mathrm{s}\right)$} \\
\hline & & $t_{i}$ & $t_{p}$ & $t_{1}$ & $t_{f}$ & $t_{u}$ & \\
\hline \multirow{3}{*}{ In-service } & 32 & \multirow{3}{*}{2.69} & 0.82 & 3.51 & 8.45 & 11.96 & 0.77 \\
\hline & 25 & & 1.05 & 3.74 & 6.60 & 10.34 & 0.77 \\
\hline & 8 & & 3.28 & 5.97 & 2.11 & 8.08 & 0.85 \\
\hline \multirow{3}{*}{ Wetting-drying cycles } & 32 & \multirow{3}{*}{0.55} & 0.82 & 1.37 & 8.45 & 9.82 & 0.16 \\
\hline & 25 & & 1.05 & 1.60 & 6.60 & 8.20 & 0.16 \\
\hline & 8 & & 3.28 & 3.83 & 2.11 & 5.94 & 0.17 \\
\hline
\end{tabular}

Table 11. Durability estimations for roof girder

\begin{tabular}{|c|c|c|c|c|c|c|}
\hline \multirow{2}{*}{ Exposure condition } & \multirow{2}{*}{$\phi(\mathrm{mm})$} & \multicolumn{5}{|c|}{ Service life estimations (years) } \\
\hline & & $t_{i}$ & $t_{p}$ & $t_{l}$ & $t_{f}$ & $t_{u}$ \\
\hline \multirow{4}{*}{ In-service } & 25 & \multirow{3}{*}{65.67} & 1.05 & 66.72 & 6.60 & 73.32 \\
\hline & 10 & & 2.62 & 68.29 & 2.64 & 70.93 \\
\hline & 8 & & 3.28 & 68.95 & 2.11 & 71.06 \\
\hline & 15.24 & 150.72 & N.A. & 150.72 & N.A. & 150.72 \\
\hline \multirow{4}{*}{ Wetting-drying cycles } & 25 & \multirow{3}{*}{13.78} & 1.05 & 14.83 & 6.60 & 21.43 \\
\hline & 10 & & 2.62 & 16.40 & 2.64 & 19.04 \\
\hline & 8 & & 3.28 & 17.06 & 2.11 & 19.17 \\
\hline & 15.24 & 30.55 & N.A. & 30.55 & N.A. & 30.55 \\
\hline
\end{tabular}

